\title{
Bjomédica
}

Artículo de Revisión

\section{Mecanismos de resistencia antifúngica de los azoles en Candida albicans. Una revisión}

Karina López-Ávila ${ }^{1}$, Karla R. Dzul-Rosado ${ }^{1}$, César Lugo-Caballero ${ }^{1}$, Juan J. Arias-León ${ }^{2}$, Jorge E. Zavala-Castro ${ }^{1}$

${ }^{1}$ Laboratorio de Enfermedades Emergentes y Re-emergentes, Centro de Investigaciones Regionales "Dr. Hideyo Noguchi", Universidad Autónoma de Yucatán. ${ }^{2}$ Unidad Interinstitucional de Investigación y epidemiológica, Facultad de Medicina, Universidad Autónoma de Yucatán

\section{Autor para correspondencia}

Nombre: Karla Dzul-Rosado

Institución: Universidad Autónoma de Yucatán.

Departamento: Laboratorio de Enfermedades emergentes y Re-emergentes. Centro de Investigaciones Regionales "Dr. Hideyo Noguchi".

Dirección: Av. Itzáes No. 490 x 59 CP 97000. Mérida, Yucatán. México.

E-mail: karla.dzul@correo.uady.mx

Recibido: el 7 de agosto de 2015 Aceptado para publicación: el 25 de noviembre de 2015.

Copyright (C) 2016 por autores (s) y Revista Biomédica.

Este trabajo esta licenciado bajo las atribuciones de la Creative Commons (CC BY).

http://creativecommons.org/licenses/by/4.0/

\section{(c) (i) Open Access}




\section{López-Ávila et al}

\section{Resumen}

Candida albicans es una levadura comensal capaz de causar una infección oportunista en hospederos susceptibles denominada candidiasis. El tratamiento para combatir la candidiasis puede ser tópico o sistémico según el tipo de infección, los antifúngicos más utilizados son los derivados imidazólicos (fluconazol, itraconazol, ketoconazol, miconazol etc.), sin embargo en la actualidad se observa una disminución en la efectividad de estos medicamentos, es decir, un fenómeno de resistencia de parte del microorganismo a estos fármacos, esto debido principalmente, al surgimiento de levaduras resistentes, a la aparición de nuevas especies patógenas, a la prescripción irracional de antimicóticos como

profilaxis y al aumento de las dosis terapéuticas. Existen dos mecanismos por los que Candida puede adquirir resistencia a un azol. El primero es por mutaciones moleculares de la enzima diana del antifúngico, como la alteración de las enzimas relacionadas en la síntesis del ergosterol y el segundo por la alteración en las bombas de expulsión: ATPbinding cassette $(A B C)$ y facilitadores mayores $(\mathrm{MF})$. En este trabajo se resumen los principales mecanismos de resistencia en Candida y la importancia de hacer pruebas de susceptibilidad con el fin de brindar un tratamiento adecuado para este tipo de infecciones oportunistas.

Palabras Clave: Cándida, resistencia antifúngica, mecanismos de resistencia

\section{Abstract}

\section{Mechanisms of antifungal resistance of azoles in Candida albicans. A review}

Candida albicans is a commensal yeast capable of causing an opportunistic infection called candidiasis in susceptible hosts. Treatment to combat Candida may be topical or systemic according to the type of infection and the imidazole derivatives (fluconazole, itraconazole, ketoconazole, miconazole, etc.) are the antifungals most widely used. However, resistance to these drugs is observed by a decrement in their effectiveness. This is mainly due to the emergence of resistant yeasts and of new pathogenic species, as well as to the irrational prescribing of antifungal prophylaxis and the use of higher therapeutic doses. There are two 
mechanisms by which Candida can acquire an azole resistance, the first is by molecular mutations of antifungal target enzyme, as the alteration of enzymes related to the synthesis of ergosterols and the second by change in the efflux pumps, such as those of ATP-binding cassette and the higher facilitators. In this work the main mechanisms of resistance to Candida and the importance of performing susceptibility tests in order to provide an adequate treatment for this type of opportunistic infections are summarized.

Keywords: Candida, antifungal resistance, mechanisms of resistance.

\section{INTRODUCCIÓN}

Las micosis son infecciones causadas por hongos que afectan a cualquier tejido; capaces de producir un cuadro clínico leve, moderado, grave o incluso mortal; que afectan a cualquier edad, sexo, condición socioeconómica y que comparten con las infecciones parasitarias, bacteriológicas y virales la misma importancia médica (1). Dentro de las micosis, las especies de Candida representan más del $80 \%$ de todas las infecciones nosocomiales; en tanto que algunas especies de Aspergillus representan el $10-20 \%$ restante (2).

Se ha observado un incremento importante en el número de pacientes con micosis que no responden a los tratamientos, siendo el uso inadecuado de los medicamentos para su manejo, el principal factor que contribuye a la resistencia en levaduras como Candida spp. El posterior surgimiento de los azoles en la década de los setenta y los triazoles, con su representante más importante, el fluconazol, a partir de los años ochenta, ha permitido su uso más generalizado, entre otras razones porque coincidió con la pandemia de SIDA y las indicaciones terapéuticas para este síndrome. Además las ventajas farmacocinéticas del fluconazol en relación con su posología y la disponibilidad en el mercado facilitaron su uso. 3,4

En este trabajo se resumen los principales mecanismos de resistencia en Candida y la importancia de hacer pruebas de susceptibilidad con el fin de brindar un tratamiento adecuado para este tipo de infecciones oportunistas.

Candida spp. son levaduras diploides sexuales eucariotas del reino hongos, de las cuales se han identificado más de 150 especies, pero sólo un pequeño número son patógenos humanos. Los miembros del género Candida son muy heterogéneos por lo que crecen como levaduras (blastosporas), o en forma filamentosa (pseudohifas, pseudomicelio). Candida albicans, el más importante representante de esta familia, forma parte normal de la microbiota humana (5). 


\section{López-Ávila et al}

Candida albicans, es el patógeno aislado con mayor frecuencia en niños, neonatos y en unidades de cuidados intensivos; y se asocia principalmente con el uso de catéteres venosos centrales (5). De manera similar, se ha asociado con la formación de biopelículas sobre catéteres, prótesis dentales o cardiacas y otros dispositivos biomédicos; convirtiéndose en un foco de diseminación de la infección, lo que entorpece las funciones propias de estos dispositivos, incrementa la estancia hospitalaria y por ende, los costos de atención y la mortalidad $(6,7)$. Se ha documentado que este patógeno presenta resistencia intrínseca a varios agentes antifúngicos, particularmente azoles y polienos, aunque los mecanismos moleculares implicados en la resistencia antifúngica de las biopelículas siguen siendo poco conocidos (8).

\section{TRATAMIENTO}

Los antimicóticos pueden ser fungistáticos o fungicidas según inhiban el crecimiento o produzcan lisis de los hongos. 5 Los mas utilizados son los derivados imidazólicos que actúan en un componente importante de la membrana del hongo, el ergosterol, el cual es un lípido de la familia de los esteroles que actúa dándole fluidez, simetría e integridad; además de contribuir en funciones propias de muchas enzimas como la quitinsintetasa, que es importante para el crecimiento y división de la propia célula (Figura 1) (9,10,11). Los derivados imidazólicos inhiben las enzimas oxidativas asociadas al citocromo P450 [CYP 3A4 y CYP 2C9] (lanosterol 14- $\alpha$ desmetilasa), bloqueando la conversión de lanosterol en ergosterol, lo que produce una alteración en la permeabilidad de la membrana de las células fúngicas. Además, promueven la acumulación de peróxido de hidrógeno capaz de lesionar la estructura de los organelos intracelulares del hongo $(2,12,13)$.

En general, los azoles son medicamentos bien tolerados cuando se usan adecuadamente, considerando sus interacciones medicamentosas y efectos secundarios. Cuando son administrados por períodos prolongados, pueden elevar las enzimas hepáticas, por lo que es importante el monitoreo constante de la función hepática (14). Además, la acción fungicida requiere concentraciones muy elevadas; por este motivo, si la terapéutica a dosis fungistáticas no se administra durante un periodo suficiente, pueden producirse recaídas (12).

\section{EPIDEMIOLOGÍA DE LA RESISTENCIA ANTIMICÓTICA EN C. ALBICANS}

La resistencia es un cambio de sensibilidad o susceptibilidad al antifúngico que puede medirse in vitro por métodos de laboratorio apropiados (15). Los mecanismos de resistencia antifúngica se clasifican en dos categorías, resistencia microbiológica y resistencia clínica (16).

La resistencia microbiológica se define como el crecimiento del microorganismo a dosis normales del antifúngico, sin embargo, éste puede ser inhibido a una concentración más alta. La resistencia 
clínica se define como el crecimiento del microorganismo a pesar de la administración de un agente antifúngico lo queesto se asocia con una alta probabilidad de falla terapéutica. En otras palabras el patógeno no se puede inhibir a dosificaciones normales pero si a concentraciones más altas las cuales podrían ser no seguras para el paciente.

La determinación de la susceptibilidad a fármacos de la cepa de Candida spp. es fundamental para el establecimiento del tratamiento adecuado, porque existen cepas específicas que son intrínsecamente resistentes a los azoles; por ello, el conocimiento de la sensibilidad a cada grupo de fármacos antifúngicos de la cepa de Candida spp puede repercutir en la toma de decisiones con respecto al tratamiento y pronóstico. El estudio de vigilancia antifúngica Artemis DISK (1997 a 2003) menciona que en 10 especies la resistencia al fluconazol se incrementó de manera notable: C. albicans 0.8 a $1.5 \%$, C. tropicalis 3 a $6.6 \%$, C. parapsilosis 2 a $4.2 \%$, C. lusitaniae 1.6 a $6.6 \%$ y C. kefyr 0 a $5.7 \%$; en otras especies se ha mantenido durante 6.5 años (17). En México, aunque no se han cuantificado los casos de resistencia en hospitales de atención general y de especialidades, se ha observado un incremento importante en el número de pacientes con micosis que no responden a los tratamientos (4).

\section{MECANISMOS DE RESISTENCIA ANTIFUNGICA EN C. ALBICANS}

La infección por C. albicans va a depender de diversos factores de virulencia, particularmente de su capacidad de adhesión. Esta capacidad es esencial para la patogenicidad porque favorece la formación de un complejo denominado biopelícula que le permite adherirse firmemente propiciando la invasión y diseminación de la infección, actuando como un importante mecanismo de resistencia antifúngica (18). Existen estudios que reportan una mayor resistencia de células en biopelículas en comparación con las que crecen en suspensión, los cuales sugieren que la formación de capas de células confiere protección a los microorganismos en las capas internas $(19,20)$.

En cuanto a las características genómicas de C. albicans relacionadas con resistencia, se han descrito mutaciones en los genes que codifican para la síntesis de ergosterol de la membrana plasmática, o bien con la sobreexpresión de genes que codifican para bombas de expulsión de fármacos fuera del microorganismo. 19,21 Existen dos mecanismos por los que Candida puede adquirir resistencia a un azol. El primer mecanismo se debe a mutaciones moleculares de la enzima diana del antifúngico, como la alteración de las enzimas relacionadas en la síntesis del ergosterol; el segundo mecanismo se debe a la formación de barreras de permeabilidad o sistemas de bombeo del antifúngico fuera de la célula, como la alteración en las bombas de expulsión: $A T P$-binding cassette $(A B C)$ y facilitadores mayores (MF) (22). 


\section{López-Ávila et al}

\section{ALTERACIÓN DE LAS ENZIMAS REALCIONADAS EN LA SÍNTESIS DEL ERGOSTEROL}

El análisis de los esteroles en una célula puede proporcionar gran información relacionada con las alteraciones que se han producido en una cepa resistente. Las modificaciones en la vía del ergosterol no solo generan resistencia al azol al cual está expuesto, sino también a otros fármacos con los que posteriormente pudiera entrar en contacto. 23

En la vía metabólica de la síntesis del ergosterol, el lanosterol y sus derivados, el sustrato es la enzima 14 alfa-lanosterol desmetilasa por lo que en la enzima dará lugar a la acumulación de 14alfa-metil esteroles, especialmente 14 alfa-metil facosterol y el 14 $\alpha$ metil-diolergosta-8,24(28)-dien-3b, 6alfadiol. En células tratadas con azoles, la presencia de $14 \alpha$-metil esteroles puede modificar la función y fluidez de la membrana plasmática, su acumulación causa la detención del crecimiento del microorganismo, sin embargo, es tolerado por C. albicans. Estudios recientes sugieren que la acumulación del compuesto diol también detiene el crecimiento de C. albicans, sin embargo, sus efectos tóxicos son eliminados gracias a una mutación en el gen ERG3, que codifica para C-5 esterol desaturasa, que es responsable de la resistencia a los azoles y moderadamente a la anfotericina B $(3,23,24)$.

La enzima 14 alfa-lanosterol desmetilasa es producto del gen CYP51/ERG11, perteneciente a la familia del gen CYP51 el cual codifica proteínas que catalizan la 14 alfa-desmetilación del lanosterol. En la actualidad, se cuenta con la secuencia del gen y han sido detectadas varias alteraciones genéticas que se asocian con el gen ERG11 de C. albicans, incluyendo mutaciones puntuales en la región de codificación, la sobreexpresión y la amplificación (que conduce a la sobreexpresión) así como y la conversión génica o recombinación mitótica $(16,25,26)$.

Se ha identificado una mutación puntual de ERG11 en aislamientos clínicos resistentes, presentándose una sustitución de arginina por lisina en el aminoácido 467 del gen ERG11, que contribuye a la resistencia a los azoles.16, 26 También la sobreexpresión del gen ERG11 origina resistencia a los azoles, ya que se ha demostrado un aumento de la transcripción de este durante la exposición a los antifúngicos azólicos, incluso en células sensibles (25). Se piensa que este aumento se debe a la respuesta de la célula, a la disminución del ergosterol o a la acumulación de esteroles tóxicos. Los cambios en los niveles de expresión de CYP51 pueden ocasionar el desarrollo progresivo de resistencia a los azoles (16) puesto que se ha demostrado la existencia de un activador de la transcripción en el promotor del CYP51 en cepas resistentes (25) El número de copias de esta secuencia repetida en tándem se correlaciona con un plásmido que presente resistencia al itroconazol 
y que contiene el gen CYP51. Así pues, parece claro que la resistencia a los azoles es producida por amplificación o hiperexpresión de la diana de los azoles (27).

\section{Alteración en las bombas de expulsión: ATP-binding cassette (ABC) y Facilitadores Mayores} (MF). Los transportadores ATP-binding cassette (ABC) y Facilitadores mayores (MF) son un sistema de bombeo activo mediado por ATP, se localizan en la membrana citoplasmática y contribuye a la resistencia de casi todos los azoles, expulsando el fármaco hacia el exterior de la célula. Los transportadores $\mathrm{ABC}$ son codificados por los genes CDR (Candida Drug Resistance) y los transportadores MF son codificados por los genes MDR (Multidrug Resistance). La sobreexpresión de los transportadores es la causa más frecuente de resistencia a los antifúngicos (todos los azoles), mientras que la sobreexpresión por los genes $M D R$ sólo confiere resistencia al fluconazol En una célula susceptible, los antifúngico azólicos entran por difusión pasiva actuando sobre la enzima lanosterol desmetilasa, que es producto del gen $E R G 11$, lo cual inhibe la síntesis del ergosterol. Estas células sensibles presentan expresión de niveles bajos de los genes $C D R$ y el gen $M D R$. En una célula resistente, los azoles son menos efectivos contra el lanosterol 14-alfa-desmetilasa por la sobreexpresión de los genes CDR y MDR. Las células resistentes pueden tener uno o ambos mecanismos de resistencia, (Figura 2) $(27,28,29,30)$.

\section{FACTORES EXTERNOS QUE CONTRIBUYEN A LA RESISTENCIA DE $C$ ALBICANS.}

Factores farmacológicos. Diversos factores relacionados a la farmacocinética, farmacodinamia, interacciones fármaco-fármaco o bien con la dosificación de los antifúngicos se encuentran asociados con la resistencia antimicótica (28). Los antifúngicos presentan con frecuencia efectos secundarios y colaterales, por lo que su margen terapéutico es estrecho, limitando su utilización. Cada uno muestra características farmacológicas distintas, que deben tomarse en consideración a la hora de tratar a enfermos con micosis sistémicas. El perfil de actividad de los azoles depende de cada fármaco, pero en términos generales, muestran un espectro de acción amplio (31). La resistencia ante los tratamientos antimicóticos no es el único motivo de preocupación; también la toxicidad y las interacciones medicamentosas clínicamente importantes a través de sus efectos sobre las enzimas humanas del citocromo P450, motivan a la realización de estudios farmacocinéticos profundos de estos compuestos, contemplando los grupos poblacionales a los que van dirigidos los tratamientos, además de las características demográficas, clínicas y genéticas de cada individuo y del contexto ambiental en el que éste se desarrolla. Por otro lado, las vías de administración son otra línea de investigación para encontrar una formulación con la capacidad de integrar todo el compuesto activo, causando la menor toxicidad posible (32). Los azoles pueden interactuar con fármacos favoreciendo la disminución en el pH gástrico, lo cual altera su absorción hasta un $40 \%$ por ser altamente lipofílicos. 


\section{López-Ávila et al}

También pueden inducir cambios en la pKa de otros medicamentos y tener múltiples interacciones medicamentosas (especialmente, voriconazol e itraconazol), produciendo hepatotoxicidad, aunque este efecto es más raro con los nuevos azoles.33 Se ha demostrado que la acumulación de los azoles como el ketoconazol, altera la síntesis de la membrana celular de los hongos, previene la formación de las seudo hifas de Candida e incrementa la fagocitosis de los hongos; aunque es uno de los fármacos más utilizados en la onicomicosis, su toxicidad hepática es muy importante. 34 La mayoría de los azoles, incluyendo el fluconazol, el itraconazol y el posaconazol, deben evitarse, en general, en mujeres embarazadas, debido a la posibilidad de defectos congénitos asociados con su uso (35).

Factores relacionados al huésped. Candida albicans tiene varios atributos de virulencia para colonizar el huésped y ocasiona daño de forma directa, al activar, resistir o desviar los mecanismos de defensa del mismo.36 Las infecciones oportunistas se presentan fundamentalmente en huéspedes inmunocomprometidos con disfunción de mecanismos de defensa. Entre los factores epidemiológicos que contribuyen para la presencia de estas infecciones se encuentra el aumento de la población susceptible, mayor número de pacientes con VIH-SIDA, pacientes oncológicos, pacientes trasplantados y pacientes con enfermedades autoinmunes.

Así mismo, este hongo, ha sido el principal patógeno y, actualmente, es responsable de 59\% de las septicemias a nivel mundial y de $45 \%$ en Latinoamérica; es el cuarto patógeno en frecuencia aislado a partir de hemocultivos en caso de infecciones nosocomiales, de 25 a $50 \%$ ocurre en la unidad de cuidados intensivos. La mortalidad se reporta entre 29 y $40 \%$ (37). Los pacientes oncológicos pueden padecer de inmunosupresión por su misma enfermedad, por un padecimiento concomitante, puesto que la neutropenia característica de estos pacientes predispone a infecciones por Candida y Aspergillus. Se ha reportado que el $80 \%$ de las infecciones fúngicas son en pacientes con cáncer y en más de 50\%n por C. albicans (38). En los pacientes trasplantados, estas infecciones son la más importantes, en el trasplante de hígado, la candidiasis son de un 62 a 83\%, riesgo que se ve influido por el procedimiento quirúrgico; en, de los pacientes trasplantados de riñón, la infección es hasta de un $95 \%$, la mayoría se limita al tracto genitourinario y sólo 5\% presenta enfermedad diseminada. Los factores de riesgo son diabetes, diálisis, enfermedad hepática.39 En pacientes con VIH-SIDA, las más comunes son la candidiasis esofágica, vaginal, traqueal, bronquial o pulmonar. En cuanto al conteo de linfocitos T CD4 con el que se presenta esta infección, en diversas series se documentan conteos variables para las diferentes formas de candidiasis mucocutánea y, generalmente, se considera que los pacientes con candidiasis orofaríngea presentan conteo de CD4 menor de 300 células/ $\mu 1$, a diferencia de la infección vulvo-vaginal que generalmente se asocia a conteos mayores de 300 CD4/ $\mu 1$. Algunos autores plantean que con conteos de CD4 menores de 300 células/ $\mu 1$, se presentan 
infecciones recurrentes y estas infecciones se convierten en marcadores de progresión de la enfermedad.40 Debido a que muchos de los factores de riesgo no son prevenibles o modificables, se requiere proteger a los pacientes susceptibles a la exposición a hongos. Aún queda por definir el tipo de paciente, el agente antifúngico, la vía de administración, el momento adecuado para la terapia profiláctica y el correcto seguimiento de la dosis y horarios para su administración. 39

\section{MÉTODOS PARA LA DETECCIÓN DE LA RESISTENCIA ANTIFUNGICA}

La cuantificación de la actividad in vitro de los antifúngicos se evalúa habitualmente mediante algunas de las variantes de los métodos de dilución. Los métodos utilizados para su determinación pueden realizarse en medios sólidos (dilución en agar) o líquidos (dilución en caldo). De manera general, se utilizan diluciones dobles seriadas de un antifúngico determinado para enfrentar a una suspensión fúngica: la menor concentración de antifúngico (expresada en unidades $/ \mathrm{ml} \mathrm{o} \mathrm{mg} / \mathrm{ml}$ ) que inhibe el desarrollo del hongo se denominará Concentración Mínima Inhibitoria (CMI). Estos resultados pueden ser interpretados y trasladados a las categorías cualitativas de sensible (S), moderadamente sensible (MS), intermedio (I) o resistente (R). La CMI se ha establecido como "gold standard" frente a otros métodos que evalúan susceptibilidad antifúngica; además de confirmar resistencias inusuales, da respuestas definitivas cuando el resultado obtenido por otros métodos es indeterminado (41-44).

Actualmente, hay disponibles dos comités que se encargan de la determinación de resistencia antifúngica: El Instituto de Estándares para el Laboratorio y la Clínica (CLSI por su sigla en inglés) en Estados Unidos y el subcomité para las Pruebas de Sensibilidad Antifúngica de la Unión Europea, de la Sociedad de Microbiología Clínica y Enfermedades Infecciosas (EUCAST, por sus siglas en inglés), en Europa. Ambos cuentan con estándares que permiten determinar la concentración mínima inhibitoria frente a las levaduras, permitiendo conocer el perfil de sensibilidad de las distintas especies y permitir al igual la detección de resistencia con el fin de elegir el tratamiento inicial adecuado. El objetivo de ambos comités ha sido establecer puntos de corte para interpretar los resultados de los estudios de sensibilidad. Actualmente, los procedimientos del EUCAST y del CLSI para definir puntos de corte son muy similares y se fundamentan en el análisis poblacional de las CMI de los microorganismos, así como en la aplicación de diferentes variables farmacocinéticas y farmacodinámicas, que permiten relacionar los resultados del antibiograma con la respuesta clínica a un determinado antimicrobiano. Asimismo, se han definido los puntos de corte epidemiológicos, valores que ayudan a separar la población normal sensible de un grupo de microorganismos de la población resistente, que en muchas ocasiones presenta mecanismos de resistencia. Estos puntos de 


\section{López-Ávila et al}

corte epidemiológicos pueden utilizarse para interpretar los resultados de los estudios de sensibilidad, en casos en los que no hay suficiente información para establecer puntos de corte clínico (46-48).

El CLSI, desarrolló la metodología para pruebas de sensibilidad antifúngica para Candida spp. y Cryptococcus neoformans por microdilución en caldo (M27-A2), como estándar de referencia para evaluar la sensibilidad de diferentes especies micóticas a agentes antifúngicos. Con base en estos estudios, el subcomité EUCAST, propuso un método de referencia de microdilución en caldo para determinar la sensibilidad de las levaduras, que fue desarrollado para probar clínicamente aquellas que puedan fermentar significativamente la glucosa, el cual es válido principalmente para Candida spp. El objetivo del subcomité de AFST del EUCAST fue proponer una modificación de este método de referencia que incluye: el suplemento al medio RPMI 1640 (2\% de glucosa) y el uso de un tamaño de inóculo de trabajo diferente (1X106 - 5X $106 \mathrm{UFC} / \mathrm{ml})$, cuya finalidad es obtener un mejor crecimiento de la levadura, lo que junto a la implementación de la lectura espectrofotométrica permite simplificar la determinación e interpretación de las CMI y realizar la prueba de sensibilidad antimicótica de una manera más fácil y comprensible. Esta metodología es similar a la de referencia CLSI M27-A2, pero con modificaciones de los parámetros de la prueba, con el objetivo de obtener lecturas precisas en tiempos más cortos, proporcionando resultados rápidos sin aumentar el costo de las pruebas, se considera un método de referencia a partir del cual se han podido desarrollar métodos alternativos más objetivos, prácticos y rápidos para su uso en el laboratorio clínico de rutina $(49,50)$.

\section{DISCUSIÓN}

En las últimas décadas se han producido cambios sustanciales en el mundo de la micología médica, gracias a los avances diagnósticos, quirúrgicos y farmacológicos iniciados a finales de los años 1960 que vinieron a revolucionar la medicina moderna. Sin embargo, estos avances aumentaron las complicaciones iatrogénicas entre las que se cuentan las infecciones oportunistas cuasadas por microorganismos saprófitos o ambientales de escasa virulencia, como Candida spp. y Aspergillus spp., se convirtieron en patógenos que podían causar cuadros infecciosos mortales. C. albicans tiene varios atributos de virulencia para colonizar el huésped y ocasionar daño de forma directa, al activar, resistir o desviar los mecanismos de defensa del mismo. Los factores de virulencia expresados o requeridos por el microorganismo para causar infección pueden variar según el tipo, el sitio y la naturaleza de las defensas del huésped.

La resistencia a los antifúngicos es un serio problema de salud sobre todo para pacientes inmunocomprometidos debido a la gravedad de las infecciones fúngicas las cuales pueden ser fatales, los fármacos que generan mayor resistencia son los azoles. 
El carácter multifactorial de la resistencia de C. albicans a los fármacos antifúngicos azólicos existentes hace necesario la adopción de nuevas estrategias para combatirla, como son el desarrollo de moléculas más potentes, la investigación de nuevos antifúngicos con nuevas dianas y mecanismos de acción, así como combinaciones con inhibidores de los transportadores activos de membrana.

Es importante analizar y mejorar las medidas profilácticas que se dan a los pacientes porque son las principales causas del desarrollo de resistencia a los antimicóticos teniendo gran influencia en el éxito del tratamiento. También es necesario que las pruebas de sensibilidad se realicen de manera rutinaria permitiendo obtener una información más precisa de resistencia o sensibilidad. Sin embargo, la pregunta que se continúa planteando es que, habiendo todos estos estudios acerca de la resistencia a ciertos antifúngicos ¿Por qué se sigue presentando este problema? H hay que considerar que es un problema complejo, que además de implicar los factores donde se puede tener influencia como por ejemplo la automedicación o bien llevar a término los esquemas terapéuticos, existen otros factores que se encuentras fuera de nuestro alcance como la presencia de mutaciones moleculares presentes en el genoma de los hongos que pueden ocasionar que determinado antifúngico ya no sea efectivo.

\section{Referencias}

1. López R. Importancia actual de la micología médica en México. Gac Méd Méx. 2008 Mar; 144 (2):121-122.

2. Hernandez O, Espejel J, Barón H, Maldonado J, Conde J. Terapia de descontaminación selectiva del tracto digestivo como profilaxis antifúngica en pacientes críticos. Clinica-UNR.org. 2009 jul; 1-7.

3. Gómez C. Candida Yeast resistance to fluconazol. Infect. 2010 dec; 14(2):172-180.

4. Manzano P, Mendez L, Hernández F, López M. La resistencia a los antifúngicos: un problema emergente en México. Gac Med Mex. 2008 oct; 144 (1): 23-26.

5. Castrillon L, Palma A, Padilla M. Biopeliculas fúngicas. Dermatol Rev Mex. 2013 jun; 57(5): 350361.

6. Samaranayake I, Anil S, Hashem M, Vellappally S, Cheung B. Human Serum potentiates the expression of genes associated with antifungal drug resistance in C. albicans biofilms on central venous catheters. Mycopathology. 2015 apr; 179(3): 195-204.

7. Veiyappan G, Rossignol T, D'Enfert C. Interaction of Candida albicans biofilms with antifungals: Transcriptional response and binding of antifungals to beta-glucans. Antimicrob Agents Chemoters. 2010 May; 54(5): 2096-2111.

8. Tobar E, Silva F, Olivares R. Gaete P, Luppi M. Invasive candidiasis in critically ill adult patient. Rev chil Infectol. 2011 feb; 28(1): 41-49.

9. Chiocchio V, Matković L. Determination of Ergosterol In Cellular Fungi By HPLC a Modified Technique. J. Argent. Chem. Soc.2011 Jul; 98:10-15.

10. Martinez M, Peres N, Rossi A. Antifungal resistance mechanisms in Dermatophytes. Mycopathologia. 2008; 166:369-383.

11. Rivas G, Cardona N. Antimicóticos de uso sistémico: ¿Con que opciones terapéuticas contamos? CES Med.2009 jun; 23(1):61-76. 


\section{López-Ávila et al}

12. Catalán M, Montejo J. Antifúngicos sistémicos. Farmacodinamia y farmacocinética. Rev Iberoam Micol. 2006 oct; 23:39-49.

13. González N, Saltigeral P. Guía antimicrobianos, antivirales, antiparasitarios, antimicóticos e inmunomoduladores. México. Trillas; 2006.

14. Escobar C, Zuluaga A. Nuevos antimicóticos y su uso en dermatología. Med Cutan Iber Lat Am. 2004 dec; 32(6):231-242.

15. Gutiérrez M, Araiza J, Hernández M, Chávez J, Rodríguez O, Bonifaz A. Estudio in vitro de antimicóticos contra cepas de Candida aisladas de pacientes del Hospital general de México OD. Dermatol Rev Mex. 2012 mar; 56(2): 93-101.

16. Pfaller M. Antifungal drug resistance: Mechanisms, Epidemiology, and consequences for treatment. Am J Med. 2012 dec; 125(1): 3-13.

17. Torre V, Martínez M, Reséndiz J. Risk factors and Epidemiology of candidemia at Hospital Juárez de México. Med Int Mex. 2014 Dec; 30(2):121-132.

18. Guango M, Santander G, Villamarín N. Micosis Invasiva. Medwave. 2008 dic; 8(11): 609-14.

19. Dhale R, Ghorpade M, Dharmadhikari C. Comparison of various Methods used to detect Biofilm Production of Candida Species. J Clin Diagn Res. 2014 Nov; 8(11):18-20.

20. Ibrahim N, Melake N, Somily Ali, Zakaria A, Baddour M, Mahmoud A. The effectof antifungal combination on transcripts of a subset of drug resistance genes in clinical isolates of Candida species induced biofilms. SPJ. 2015 Jan; 23(1): 55-66.

21. Cowley S, Nobile C, Hartooni N, Newman D, Johnson A. Anaerobic Bacteria Grow within Candida albicans Biofilms and Induce Biofilm Formation in Suspension Cultures. Curr Biol. 2014 Oct; 24(20): 2411-2416.

22. Ortigoza E, Arroyo D. Susceptibilidad in vitro de las especies de Candida a los antifúngicos en el Hospital de Especialidades del Centro Médico Nacional de Occidente. Med Int Méx. 2014 ago; 30(40):373-380.

23. Cowen L, Sanglard D, Howard S, Rogers D, Perlin D. Mechanism of antifungal Drug Resistance. Cold Spring Harb Perspect Med. 2014 nov; 4(11): 1-22.

24. Ahmad A, Khan A, Manzoor N, Khan L. Evolution of ergosterol biosynthesis inhibitors as fungicidal against Candida. Microbial Pathogenesis. 2010 Oct; 48 (1): 35-41.

25. Mellado E, Cuenca M, Rodríguez J. Importancia clínica de los mecanismos de resistencia de los hongos filamentosos a los antifúngicos. Enferm Infecc Microbiol Clin. 2002 jul; 20(10):523-30.

26. Fuentes M, Hermosilla G, Alburquenque C, Falconer M, Amaro J, Tapia C. Caracterización de los mecanismos de resistencia a azoles en aislados clínicos chilenos de Candida albicans. Rev Chilena Infectol. 2014 jul; 31(5): 511-517.

27. Debnath S, Addya S. Structural basis for heterogeneous phenotype of ERG 11 dependent Azole resistance in C. albicans clinical isolates. Springerplus. 2014 nov; 6(3): 660.

28. Morschhäuser J. Regulation of multidrug resistance in pathogenic fungi. Fungal Genetics and Biology. 2010 ago; 47: 94-106.

29. Cuenca M, Antifungicos en el tratamiento de las infecciones sistémicas: importancia del mecanismo de acción, espectro de actividad y resistencias. Rev Esp Quimioter. 2010 dic; 23(4): 169-176.

30. Prassad R, Goffeau A. Yeast ATP-Binding Cassette Transporters Conferring Multidrug Resistance. Annu. Rev. Microbiol. 2012 Jun; 66:39-63.

31. Ruiz I, Cuenca M. Antifúngicos para uso sistémico. Enferm Infecc Microbiol Clin. 2009; 27(6):353362.

32. Ruiz N, et al. Aspectos farmacocinéticos del fluconazol. Rev Hosp Jua Mex. 2013 mar; 80(1): 28-33.

33. Díaz A, Garcés C. Uso Actual de los antifúngicos triazoles en niños. Infectio. 2012 jun; 16(3); 8293.

34. Tapia C. Mecanismos de acción, reacciones adversas y nuevos antimicóticos. Medwave. 2005 May; 16(4):5. 
35. Pappas $\mathbf{P}$, et al. Guías de práctica clínica para el manejo de la Candidiasis. Clinical Infectious Diseases. 2009 mar; 48:1-35.

36. Castrillon L, Palma A, Padilla C. Factores de virulencia en Candida sp. Dermatología Rev Mex 2005 dec; 49(1):12-27.

37. Vásquez E, Arenas R. Micosis Oportunistas en pacientes inmunocomprometidos. Gac Méd Méx. 2008 ene; 144 (2):31-133.

38. Lacy R, et al. Micosis superficiales en pacientes oncológicos. Estudio en 98 pacientes. Med Cutan Iber Lat Am 2007 abr; 35(2):83-88.

39. Espinel I. Mechanisms of resistence to antifungal agents: Yeast and filamentous fungi. Rev. Iberoam. Micol. 2008 Jun; 25(2): 101-106.

40. Calle J, Cardona N. Micosis más prevalentes en pacientes con VIH/SIDA, correlación con el estado inmunológico del huésped. Rev Asoc Colomb Dermatol. 2009 oct; 17: 211-220.

41. López I, López G, Díaz R. Manual práctico de Microbiología. Barcelona, España. Editorial MASSON; 2005.

42. Arechavala A, et al. Identificación y sensibilidad frente a fluconazol y albaconazol de 100 cepas de levaduras aisladas de flujo vaginal. Rev Iberoam Micol 2007; 24: 305-308.

43. Hurna G., Silva M, Taboada V, Ortiz T. Concentración mínima inhibitoria y Concentración mínima bactericida de ciprofloxacina en bacterias uropatógenas aisladas en el Instituto Nacional de Enfermedades Neoplasicas. Rev Med Hered 2005 mar; 16(1):39-45.

44. Maldonado I, Fernández C, Vivot W, Domeq P, Davel G, Córdoba S. Evaluación de tres métodos hay otro para la detección de la sensibilidad In vitro de especies de Candida a los antifúngicos. Rev Argent Microbiol. 2011 jun; 43(2): 120-126.

45. Struthers K, Westron R. Clinical Bacteriology. Reino Unido. Manson Publishing Ltd; 2003.

46. Cuenca M, Alastruey A, Gómez A, Monzón A. Estudio de sensibilidad en levaduras. Actualización y novedades. Enferm Infecc Microbiol Clin. 2013;31:53-58

47. Duarte C, Pulido N, Rivas P, Sánchez R, Cortés J, Cuervo S. Comparación de métodos de microdilución CLSI M27-A2 y EUCAST en aislamientos de Candida spp. en pacientes con cáncer. Infectio. 2010 nov; 14(S2): S107-115.

48. Sanabria R, et al. Antifungal susceptibility profile of Candida spp isolates by the microdilution method. New cutoff points for fluconazole. Mem. Inst. Investig. Cienc. Salud. 2014 Jun; 12(1): 3340.

49. Zapata F, Cardona N. Lo que debemos saber sobre los métodos de sensibilidad a los antifúngicos. Rev CES Med. 2012 Jun; 26(1): 71-83.

50. Pfaller M. New Developments in the Antifungal Susceptibility Testing of Candida. Epidemiology and Clinical Lab Issues. 2008 Jun; 26(1):125-133. 


\section{López-Ávila et al}

Figuras

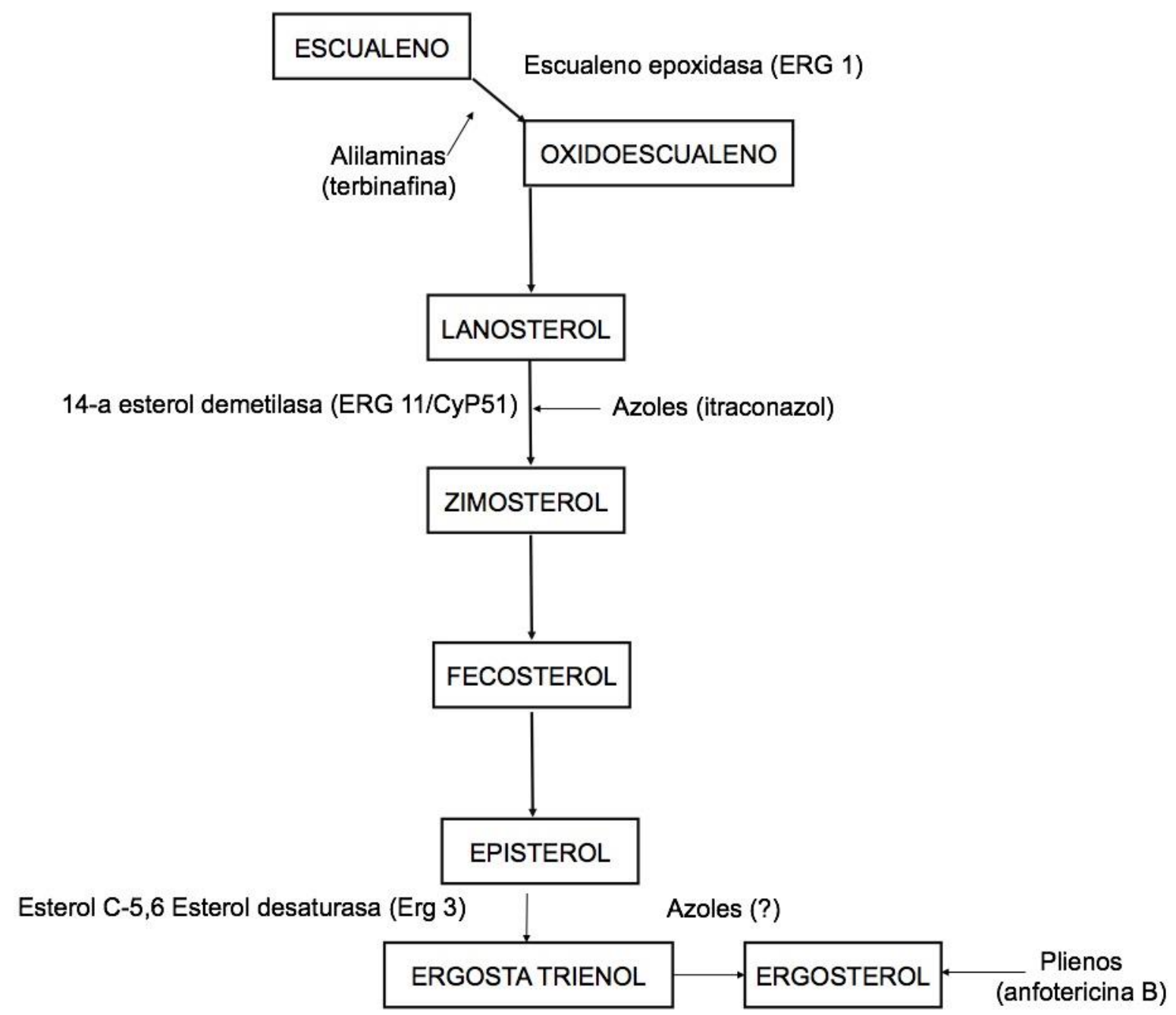

Figura 1. Mecanismo de acción de los antifúngicos que actúan en la vía de síntesis del ergosterol. 


\section{A. SUSCEPTIBILIDAD}
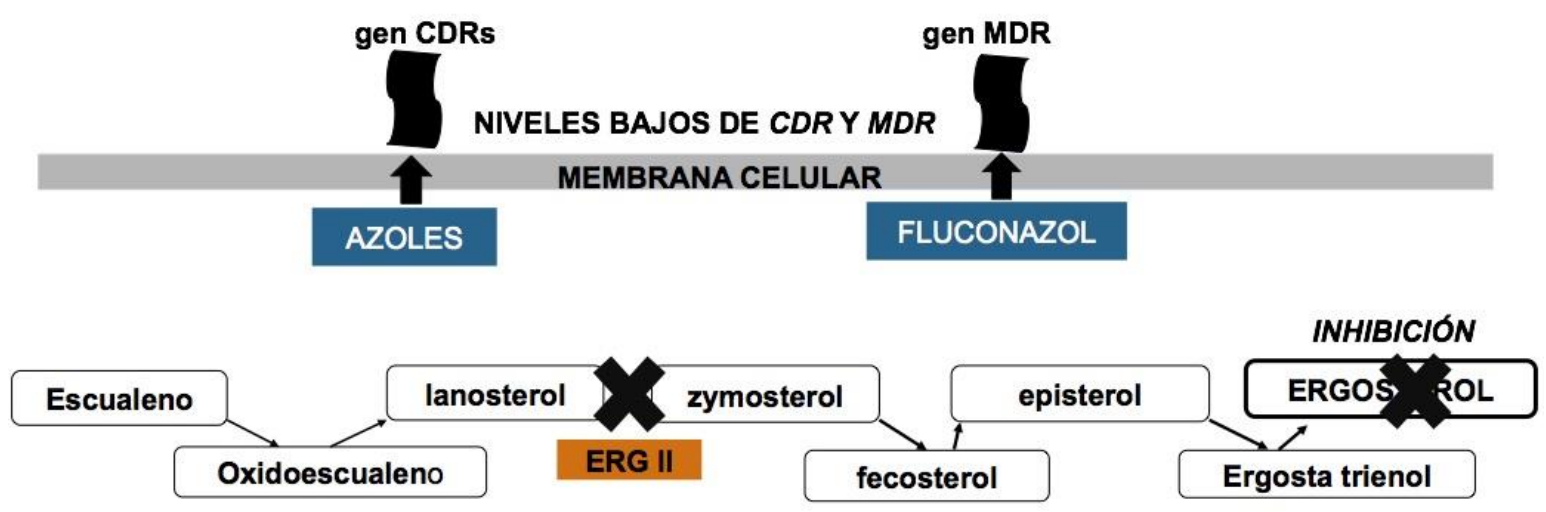

B. RESISTENCIA

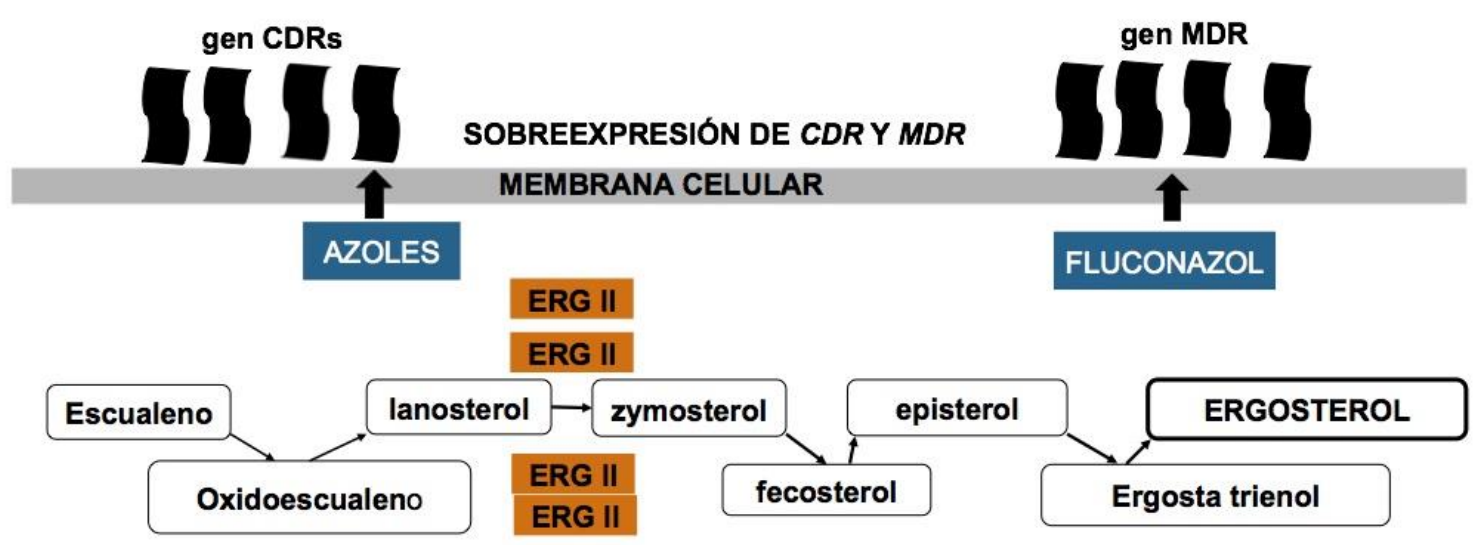

Figura 2. Alteraciones en el transporte de fármacos (sobreexpresión de bombas, transportadores $\mathrm{ABC}$ ) 